
measurement of obesity in a community. Indian f.Med Res 1984;80:365-71. $1 \mathrm{Keen} \mathrm{H}$. What's in a name? IDDM/NIDDM, type 1/type 2. Diabetic Med 1986:3:11-2.

12 Barker DJP, Gardner MJ, Power C. Incidence of diabetes amongst people aged 18-50 years in nine British towns: a collaborative study. Diabetologia 1982;22:421-5.

13 Mann JI, Lewis B, Shepherd J. Blood lipid concentrations and other cardiovascular risk factors: distribution, prevalence, and detection in Britain Br. Hed 1988;296:1702-6.

14 Multi-centre study. United Kingdom prospective diabetes study. IV. Characteristics of newly presenting type 2 diabetic patients: male preponderance and obesity at different ages. Diabetic Med 1988:5:154-9.

15 Multi-centre Study. United Kingdom prospective diabetes study. V. Charac- teristics of newly presenting type 2 diabetic patients: estimated insulin sensitivity and islet B-cell function Diabetic Med 1988;5:444-8.

16 Wilkerson HL, Krall LP. Diabetes in a New England town. JAMA 1947;135:209-16.

17 Sharp CL, Butterfield WJH, Keen H. Diabetes survey in Bedford 1962. Proc $R$ Soc Med 1964;57:193-202.

18 Massair V, Eschwege E, Valleron AJ. Imprecision of new criteria for the oral glucose tolerance test. Diabetologia 1983;24:100-6.

19 Hillson RM, Hockaday TDR, Newton DJ, Pim B. Delayed diagnosis of non insulin dependent diabetes is associated with greater metabolic and clinical abnormality. Diabetic Med 1985;2:383-6.

\title{
Adverse changes in mood and cognitive performance of house officers after night duty
}

\author{
D I Orton, J H Gruzelier
}

\begin{abstract}
The effects of long hours of work by junior doctors are the subject of growing concern. Experimental investigations of the effects of night duty on young doctors are few and have given inconclusive results. To measure the effects of long hours of work and reduced sleep on cognitive performance and mood 20 house officers ( 14 men and six women; mean age 25 , range 24-35) were examined for 35 minutes in one session towards the end of a normal working day and in a second session at the same time after working for up to 31 continuous hours with reduced sleep. The order of the sessions was counterbalanced across the subjects. Each session comprised a series of cognitive tests: choice reaction time, vigilance reaction time, and haptic sorting tests and completion of a profile of mood states and a general questionnaire. After night duty there was a significant slowing in cognitive processing together with a decline in reaction times in the vigilance test. Loss of sleep contributed only to increased variability in the choice reaction time. Significant deleterious changes in mood after night duty occurred in all the mood scales after night duty.
\end{abstract}

Continuous working may adversely affect the cognitive function and mood to the detriment of the welfare of doctors and their patients.

\section{Introduction}

There is growing concern about the desirability of junior doctors undertaking duty rosters that entail working continuously on consecutive days, typically with reduced sleep and sometimes with no sleep, that may occur twice a week or more. ${ }^{1}$ This practice has been said to encourage self reliance, affording both wider experience of clinical conditions and responsibilities and providing the necessary experience in dealing with emergencies under non-optimal conditions. Although these explanations seem valid, the risks to patients increase when errors are made by tired doctors, who lack agility in making decisions due to a slowing in cognitive functions. The personal lives of the doctors are compromised, which may lead to psychiatric problems, drug abuse, and broken marriages. ${ }^{2}$ Disillusion with hospital medicine may result, and undesirable behavioural traits that permeate future practice and lifestyle may develop..$^{2-4}$ These issues are becoming more pressing as demands grow owing to the exacting requirements of modern technology, as the number of malpractice suits increases, and as pressures mount to treat and discharge patients more quickly.
Proponents of busy night duty rosters have argued that impairment in function or mood may result from pre-existing inadequacies or reflect the natural doubts and insecurities of the novice doctor. ${ }^{5}$ Such viewpoints may be placed in better perspective if scientific investigations were to provide empirical evidence of the deleterious effects of long hours of work and loss of sleep in junior doctors. A review of existing studies shows that persuasive investigations to date have been few ${ }^{6}$ owing partly to the difficulty in undertaking occupational research of this type, which adds to the load of already tired and sometimes defensive doctors. ${ }^{7}$ We report on a study of cognitive and mood changes in 20 junior doctors at Charing Cross Hospital, all of whom were in their second house job.

\section{Subjects and methods}

We studied 20 preregistration house officers ( 14 men and six women; mean age 25 , range $24-35$ ). On average they had spent 6.75 months as house officers. Fourteen were house officers in general medicine and six were in general surgery. The subjects acted as their own controls and were tested twice, once in the midafternoon towards the end of a conventional working day that began at about 830 am and once at a similar time after they had been on duty throughout the preceding night and had started work at the usual time on the following day. Before testing the subjects were assigned randomly to two groups; half were tested first after night duty and half after a normal working day. At least one week elapsed between the sessions to minimise carryover effects. The test session lasted about 35 minutes.

Cognitive tests included choice reaction time, vigilance reaction time, haptic sorting test, and profile of mood states and general questionnaires.

Choice reaction time - The subject watched a video screen (CMB computer) and pressed a key with one hand on presentation of a vertical bar and another with the other hand in response to a horizontal bar. The stimuli were presented in a randomised sequence, and the duration between the stimuli was terminated by the response; the maximum duration of the stimulus was 1.84 seconds. Ninety stimuli were presented and divided into three equal blocks for analysis. Mean (SD) correct reaction time, the number of errors, and the standard deviation of the mean reaction time (which has been shown to increase after sleep $\operatorname{loss}^{8}$ ) were recorded.

Vigilance reaction time-One hundred letters were presented on the screen in sequence with instructions to press a key on seeing the letter $x$ but only when it had 
been preceded by the letter f. The letters were presented at regular intervals of $1 \cdot 17$ seconds for a maximum duration of 1.48 seconds, and there were 15 target responses in total. The variables measured were the same as for the test of choice reaction time and were divided into three blocks, each of five target trials.

Haptic sorting task - This was a modified version of a haptic task which entailed the subjects discriminating between plastic letters and numbers while blindfolded and sorting them according to class with only one hand at a time. ${ }^{9}$ Two sets of eight figures each were presented to the subjects and each set was sorted with the left and right hands separately. In addition, the movement time of each hand was assessed by placing the items alternately without sorting into two sorting trays. Movement time was subtracted from sorting time to obtain a measure of central processing time. ${ }^{10}$

Questionnaires-Subjects completed a profile of mood states questionnaire, " which consists of 65 five point adjective ratings from which six mood scales are derived: tension-anxiety, depression-dejection, anxiety-hostility, vigour-activity, fatigue-inertia, and confusion-bewilderment.

A general questionnaire was also completed, which included questions about length of time on duty, number of hours of sleep and its quality, and a question asked in a previous study, "Do you think that your hours on duty are so long as to impair your ability to work with adequate efficiency?"’

\section{Results}

Night duty-Table I shows the mean (SD) scores obtained for the cognitive tasks in the two sessions (after night duty and control) together with the difference in the scores. Analysis of the results by analysis of variance with the timing of the tests as a factor within subjects to examine for order effects showed that none were evident. The conditions were then compared with paired $t$ tests. Mean central processing time in the haptic sorting test was significantly slower after the subjects had been on night duty, which contrasted with only a tendency for manual movements to be slower, as assessed by mean movement time. The mean number of errors was not significantly different between sessions and was low in each case. The choice reaction time test showed no significant changes between the sessions; the mean reaction times in the vigilance test, which required sustained concentration, were, however, significantly slower and the variability of reaction

TABLE I-Mean (SD) scores of cognitive variables in 20 house officers tested after preceding night spent on or off duty (control)

\begin{tabular}{|c|c|c|c|c|c|}
\hline Variable & After night duty & Control & Difference in scores & $t$ Value & $\mathrm{p}$ Value \\
\hline \multicolumn{6}{|l|}{ Haptic sorting test: } \\
\hline Processing time (s) & $23.54(13.43)$ & $18 \cdot 39(11 \cdot 43)$ & $(4 \cdot 58)$ & $5 \cdot 04$ & $<0.001$ \\
\hline Movement time (s) & $12.55(2.23)$ & $11.95(2.09)$ & $(1.99)$ & 1.90 & 0.07 \\
\hline No of errors & $0.65(1.04)$ & $0.60(0.94)$ & $(1.08)$ & $0 \cdot 17$ & NS \\
\hline \multicolumn{6}{|l|}{ Choice reaction time: } \\
\hline Reaction time $(\mathrm{ms})$ & $0.46(0.06)$ & $0.45(0.05)$ & $(0.0001)$ & $0 \cdot 87$ & NS \\
\hline $\begin{array}{l}\text { Standard deviation of } \\
\text { mean reaction times }(\mathrm{ms})\end{array}$ & $0.07 \quad(0.05)$ & $0.45(0.06)$ & $0.0006(0.0002)$ & $0 \cdot 58$ & NS \\
\hline No of errors & $1.03 \quad(1.09)$ & $1.20(1.01)$ & $-0.675(0.76)$ & $0 \cdot 88$ & NS \\
\hline \multicolumn{6}{|l|}{ Vigilance reaction time: } \\
\hline Reaction time (ms) & $0.35(0.05)$ & $0.31 \quad(0.04)$ & $(0 \cdot 00007)$ & $6 \cdot 08$ & $<0.001$ \\
\hline $\begin{array}{l}\text { Standard deviation of } \\
\text { mean reaction times }(\mathrm{ms})\end{array}$ & $0.08 \quad(0.08)$ & $0.05(0.03)$ & $(0 \cdot 0005)$ & $2 \cdot 06$ & 0.05 \\
\hline
\end{tabular}

TABLE II - Mean (SD) scores of profile of mood states scale

\begin{tabular}{|c|c|c|c|c|c|}
\hline Variable & After night duty & Control & Difference in scores & $t$ Value & $\mathrm{p}$ Value \\
\hline Tension-anxiety & $8.9(4.52)$ & $6.7(5.09)$ & $2 \cdot 2(5 \cdot 91)$ & $2 \cdot 23$ & $<0 \cdot 04$ \\
\hline Depression-dejection & $7 \cdot 0(7 \cdot 95)$ & $3 \cdot 3(4 \cdot 00)$ & $3 \cdot 7(7 \cdot 78)$ & $2 \cdot 12$ & $<0.04$ \\
\hline Anger-hostility & $7 \cdot 6(6.54)$ & $3 \cdot 2(3 \cdot 69)$ & $4.4(5.72)$ & $3 \cdot 40$ & $<0.001$ \\
\hline Vigour-activity & $10 \cdot 3(5 \cdot 42)$ & $17 \cdot 3(4 \cdot 46)$ & $-7 \cdot 0(8 \cdot 00)$ & $6 \cdot 04$ & $<0.001$ \\
\hline Fatigue-inertia & $14 \cdot 0(5 \cdot 67)$ & $6.0(3.99)$ & $8 \cdot 0(4 \cdot 77)$ & $7 \cdot 33$ & $<0.001$ \\
\hline Confusion-bewilderment & $7 \cdot 7(3.01)$ & $4 \cdot 7(2 \cdot 41)$ & $3 \cdot 0(3 \cdot 13)$ & $4 \cdot 29$ & $<0.001$ \\
\hline
\end{tabular}

times significantly increased. Table II shows the mean (SD) scores for the profile of mood states scale. Significant alterations in mood occurred. After night duty the ratings were increased on the scales of tensionanxiety, anger-hostility, fatigue-inertia, confusionbewilderment, and depression-dejection, and the rating on the vigour-activity scale was substantially lower. In response to the specific question asking whether hours on duty were so long as to impair the ability to work with adequate efficiency, $\operatorname{six}(30 \%)$ respondents replied that this was the case often, $11(55 \%)$ occasionally, and three $(15 \%)$ sometimes, which was similar to previous findings of $34 \%, 48 \%$, and $12 \%$ respectively. ${ }^{12}$

Loss of sleep-The distribution of subjects according to their hours of sleep was: one hour (1), two hours (3), three hours (1), four hours (4), five hours (8), and six hours (3). The subjects were divided into those who had had more or less than five hours of sleep; they comprised $11 v$ nine subjects respectively. The analyses of variance were redone with hours of sleep as a grouping factor. The figure shows that choice reaction time was influenced by loss of sleep such that subjects who had had less sleep showed a decline in reaction time in the last block of trials $(t=\sqrt{4 \cdot 54} ; 16 \mathrm{df} ; \mathrm{p}<0.03)$ Otherwise, loss of sleep did not add to the effect of night duty on cognitive performance or mood.

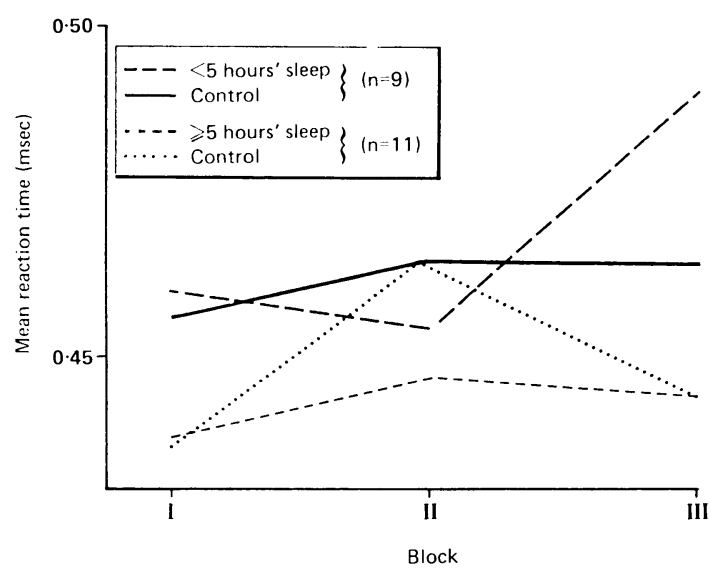

Mean choice reaction times in 20 junior doctors after less than five hour of sleep or after five or more hours of sleep compared with control conditions

\section{Discussion}

In addition to fatigue and depression, hostility, anxiety, tension, and confusion have been reported after loss of sleep together with a reduction in positive affect and friendliness. ${ }^{13-15}$ In our study the long hours of work ( 31 hours or more on duty) rather than loss of sleep itself were largely responsible for changes in cognition or mood. The decline in cognitive functions included a slowing of central processing time in the haptic sorting test and slower reactions on the vigilance task coupled with increased variability in performance indicating attentional lapses. Vigilance tasks, requiring sustained attention on a simple task with little intrinsic interest, have previously been considered to be sensitive to deprivation of sleep. ${ }^{15}$ In contrast to the cognitive changes manual movements in the sorting task showed only a tendency towards slowing, though the speed of reactions in the choice reaction time task was not affected. In terms of order of magnitude the slowing of central processing time was similar to that occurring under hypnosis, when it was coincidental with losses in memory and an altered time sense. ${ }^{10}$ In our study the cognitive changes had a counterpart in higher ratings of confusion and bewilderment.

Subdivision of house officers according to whether they slept for less than five hours or five hours or more as was done by Wilkinson $e t a^{8}$ showed that none of 
these changes varied simply with loss of sleep. This, however, did affect choice reaction time in which the ability to maintain a constant level of performance over blocks of trials was impaired. Wilkinson found the same effects after deprivation of sleep, provided the task exceeded five minutes; compensation was possible in tasks of up to five minutes' duration. ${ }^{\text {is }}$ The need to sustain performance for longer than five minutes, which also applied to our study, may have a bearing on the results of Poulton $e t a l$, who concluded from a study of 30 junior doctors who had lost between three and eight hours' sleep that the doctors could compensate on the basis of tasks of less than five minutes' duration.

Though mood ratings do not have the same objectivity as the cognitive measures, the values obtained here corroborate earlier results in which the same mood schedule was examined in a study of the effects of 24 hours' deprivation of sleep in volunteers. ${ }^{12}$ In our study the house officers showed significant deleterious changes in all the mood scales after night duty.

Laboratory evidence of the adverse effects of night duty may nevertheless underestimate their implications for the ward environment and their consequences for the doctor-patient relationship. As in previous studies the length of testing, here a 35 minute session, was necessarily curtailed to encourage cooperation with testing. Even so, many doctors were unwilling to participate. If the test sessions had been longer more complex inaccuracies in performance and cognitive functions may well have been manifested. The raised scores on the confusion-bewilderment scale suggest such a potential.
In conclusion the reduction in cognitive performance combined with the adverse changes in mood show less than desirable conditions for personal wellbeing and the practice of medicine. Superimposed night duty rosters may be a stress adversely affecting the welfare of both the doctor and the patient.

1 Social Services Committee. Medical education; with special reference to the mumber of docurs und the career structure in hospials. Session 1980-81. number of doctors and the career
London: HMSO, 1981. (No 31.)

2 Vailiant GE. Some psychologic vulnerabilities of physicians. N Engl f Med $1973 ; 287: 372-5$

3 Wilkinson RT, Tyler P, Varey C. Duty hours of young hospital doctors: effects on the quality of their work. Fournal of Occupational Psychology 1975;48 219-29.

4 Friedman RC, Kornfeld DS, Bigger TJ Jr. Psychological problems associated with sleep deprivation in interns. F Med Educ 1973;48:436-41.

5 Poulton E, Hunt G, Carpenter AL, Edwards R. The performance of junior hospital doctors following reduced sleep and long hours of work. Ergonomics 1981:21:279-95.

6 Asken MJ, Rahan DC. Resident performance and sleep deprivation. 7 Med Educ 1983;58:382-7.

Oswald I. Do we need sleep? BMA News Review. 1987:13(Oct): 16-8

7 Oswald I. Do we need sleep? BMA News Review. 1987;13(Oct):16-8. reduced sleep. Psychosonomic Science 1966;5:471-2.

9 Kugler B, Henley S. Lateral effects in the tactile modality in schizophrenia. In uruzelier J, Flor-Henry P, eds. Hemisphere asymmetry of function and
(a) Henles psychopathology. Amsterdam: Elsevier, 1979:475-90.

10 Gruzelier JH, Brow TD, Perry A, Rhonder J, Thomas M. Hypnotic susceptibility: a lateral predisposition and altered cerebral asymmetry under hypnosis. Int f Psychophysiol 1974;2:131-9.

11 McNair DN, Lorr M, Droppleman LF. Profile of mood states manual. San Diego: Educational and Industrial Testing Service, 1971

12 Wilkinson RT. Sleep deprivation. In: Edholm OG, Bacharach AL, eds. The physiology of human survival. New York: Academic Press, 1965:85-94.

13 Cutler $\mathrm{N}$. Cohen $\mathrm{H}$. The effects of one night's sleep loss on mood and memory in normal subjects. Compr Psychiatry 1974;20:61-6.

4 Webb WB, Agnew HW. The effects of a chronic limitation of sleep length. Psychophysiology 1974;11:265-74.

15 Kollar E, Slater G, Palmer J, Mandell R. Stress in subjects undergoing sleep deprivation. Psychosom Med 1964;28:101-3.

(Accepted 7 November 1988)

\title{
Lung immunoglobulins in the sudden infant death syndrome
}

\author{
Kevin D Forsyth, Sandy C Weeks, Lin Koh, John Skinner, John Bradley
}

\section{Flinders University of}

South Australia

Kevin D Forsyth, FRACP,

lecturer in paediatrics and

immunology

Sandy C Weeks, BSC, scientist, department of histopathology

John Skinner, FRCPA, associate professor, department of histopathology

John Bradley, FRCPA, associate professor, department of clinical immunology

Flinders Medical Centre, Adelaide, South Australia Lin Koh, BSC, scientist, department of clinical immunology

Correspondence to: $\mathrm{Dr}$ Kevin Forsyth, Department of Immunology, Institute of Child Health, University of London, London

WCIN 1EH

BrMed f 1989;298:23-6.

\section{Abstract}

The incidence of the sudden infant death syndrome parallels that of respiratory tract infections in the paediatric community. On the basis that the aetiology of the sudden infant death syndrome may lie in an unusual response to a trivial intercurrent respiratory infection a necropsy study was carried out investigating pulmonary immunoglobulins in 16 victims of the syndrome and a series of infants (controls) who had died of non-pulmonary causes. Compared with the controls victims of the sudden infant death syndrome had grossly raised concentrations of IgG, IgM, and to a less extent IgA in lung lavage samples. In addition, pulmonary interstitial and terminal airway cells expressing these immunoglobulins were identified far more often in victims than controls. The study failed to determine whether the increased immunoglobulin concentrations were a consequence of an unusual response to a trivial infection or an expression of otherwise altered immunological control in the respiratory tract.

Epidemiological evidence and the findings of this study suggest that the respiratory tract is the prime target organ in the sudden infant death syndrome.

\section{Introduction}

The sudden infant death syndrome is the main cause of mortality in the first year of life in developed countries. Despite extensive efforts, no unifying concept of pathophysiology can explain most cases. Analysis of epidemiological data shows that the syn- drome is more common in colder climates during the winter and that its incidence correlates with respiratory tract infections, particularly rates of admission to hospital for bronchiolitis. ${ }^{2}$ A highly significant correlation has been reported between the isolation of respiratory viruses in the general paediatric population and the incidence of the sudden infant death syndrome. ${ }^{3}$ Often victims of the syndrome have an upper respiratory tract infection in the week preceding death, ${ }^{+}$some $40-75 \%$ of victims having evidence of mild upper respiratory tract infection with various viruses. ${ }^{\varsigma}$ Hence an unusual response to a common viral pathogen is epidemiologically possible. Analysis of the immunological state of the lung may therefore help to answer whether immunological dysregulation is occurring in the sudden infant death syndrome.

The aim of this study was to measure concentrations of immunoglobulins IgG, IgA, and IgM in lung lavage samples from victims of the sudden infant death syndrome and compare them with values in controls. In addition, the presence of these immunoglobulins in cells within lung sections collected at necropsy were quantified and compared with controls.

\section{Subjects and methods}

All previously well infants who die suddenly and unexpectedly (presumptive sudden infant death syndrome) in South Australia come to necropsy at the Adelaide Children's Hospital by direction of the state coroner. We collected lung lavage samples and lung tissue from 16 such cases (mean age of victims $3 \cdot 8$ 